\title{
CHANGES IN PROPERTIES OF PEROVSKITE SOLAR CELLS DURING THEIR LIFETIME
}

\author{
Tomáš Dvořák \\ Doctoral Degree Programme (1), FEEC BUT \\ E-mail: xdvora1j@stud.feec.vutbr.cz \\ Supervised by: Vítězslav Novák \\ E-mail: novakv@feec.vutbr.cz
}

\begin{abstract}
This paper deals with the problematics of perovskite solar cells, which can be the next generation of photovoltaic solar cells. The objectives of this research are to analyse changes in perovskite solar cells. For measurements of electrical properties were used various methods such as I-V characteristic, intensity modulated photovoltage spectroscopy and dependence of photocurrent on light intensity. Measurements indicate considerable changes of performance, which resulted from aging of perovskite solar cells. Results suggest deeper observation of perovskite solar cells.
\end{abstract}

Keywords: EEICT, perovskite, solar cell, spectroscopy, light intensity.

\section{INTRODUCTION}

Photovoltaic is a well-known topic today. Since the first realization of photovoltaic cell many years have passed and developments in this sector are continuing. It can be observed that there is a progress on construction of photovoltaic cells or materials used for it. As photovoltaic panels belong to a group of renewable resources, solar panels are getting more important for society, because of the ecology aspect.

These days most of the photovoltaic solar cells are based on silicon semiconductors. However, the manufacturing of silicon of required quality is exacting and expensive. In addition, the silicon photovoltaic cells are getting to the limit of their efficiency, which is why photovoltaic cells from new materials are being researched. New materials can allow cheaper and easier manufacturing of photovoltaic cells.

Among such materials belongs perovskite. The main advantage of perovskite its simple preparation, the layer of perovskite necessary for same results as for silicon photovoltaic cells is one micrometre, when for silicon is this layer more than hundred times thicker. Due to this layer reduction, significantly lower costs can be achieved. However, perovskite solar cells need to be tested properly.

The focus of this paper is to study changes in properties of perovskite solar cells in time. First section deals with fabrication of perovskite solar cells. First section explains methods used for our measurements. Second section obtains results, which were acquired by chosen measurements. Last section obtains conclusion. 


\section{EXPERIMENTAL SECTION}

Perovskite solar cells are composed of ITO (indium tin oxide) glass covered by layers of: PEDOT (transparent antistatic conductive layer), perovskite, PCBM and aluminium electrodes.

\subsection{Preparation OF PEROVSKite SOlar CELlS}

All steps of perovskite solar cells preparation have to be made in glovebox. First step is deposition of PEDOT on ITO glass. After PEDOT deposition follows deposition of perovskite layer, before this can be made, glasses are tempered on temperature $80^{\circ} \mathrm{C}$. When glasses are tempered, they are moved on spin coater, where the perovskite is applied. After perovskite deposition, follow on annealing.

Next step is deposition of PCBM layer. PCBM layer is applied via spin coater and pipette. When this layer is done, the cleaning of glass has to be done on the place where cathode band belongs.

After PCBM layer application follows deposition of aluminium electrodes. Deposition is done by vacuum evaporation.

Last step is application of epoxy resin and cover glass. Epoxy resin is hardened by UV light [1].

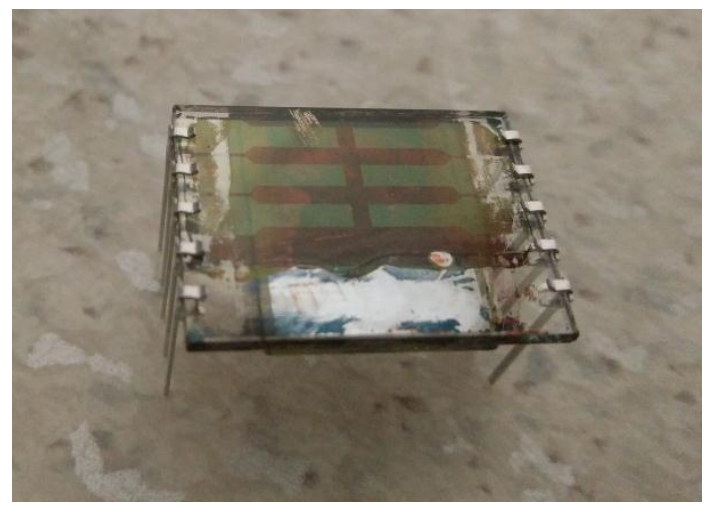

Picture 1: Finished perovskite solar cell

\subsection{METHODS OF SOLAR CELLS MEASUREMENTS}

All measurements were executed on CIMPS device with two light sources. First light source WLR02 s/n LS 1367 have wide spectrum LED diode, second light source TLS03 1366 contains monochromatic light sources with wavelength from $290 \mathrm{~nm}$ to $1090 \mathrm{~nm}$.

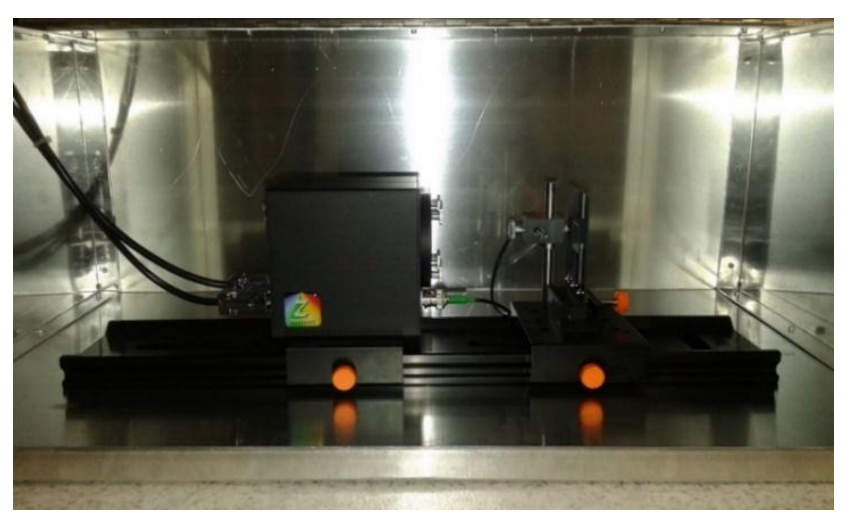

Picture 2: Light source and solar cell holder with light sensitive sensor.

I-V characteristic shows dependence of current on potential. From this characteristic is possible to gain MPP (Maximum Power Point), where the maximum output is gained. Light intensity of light source was set on $350 \mathrm{~W} / \mathrm{m}^{2}$. 


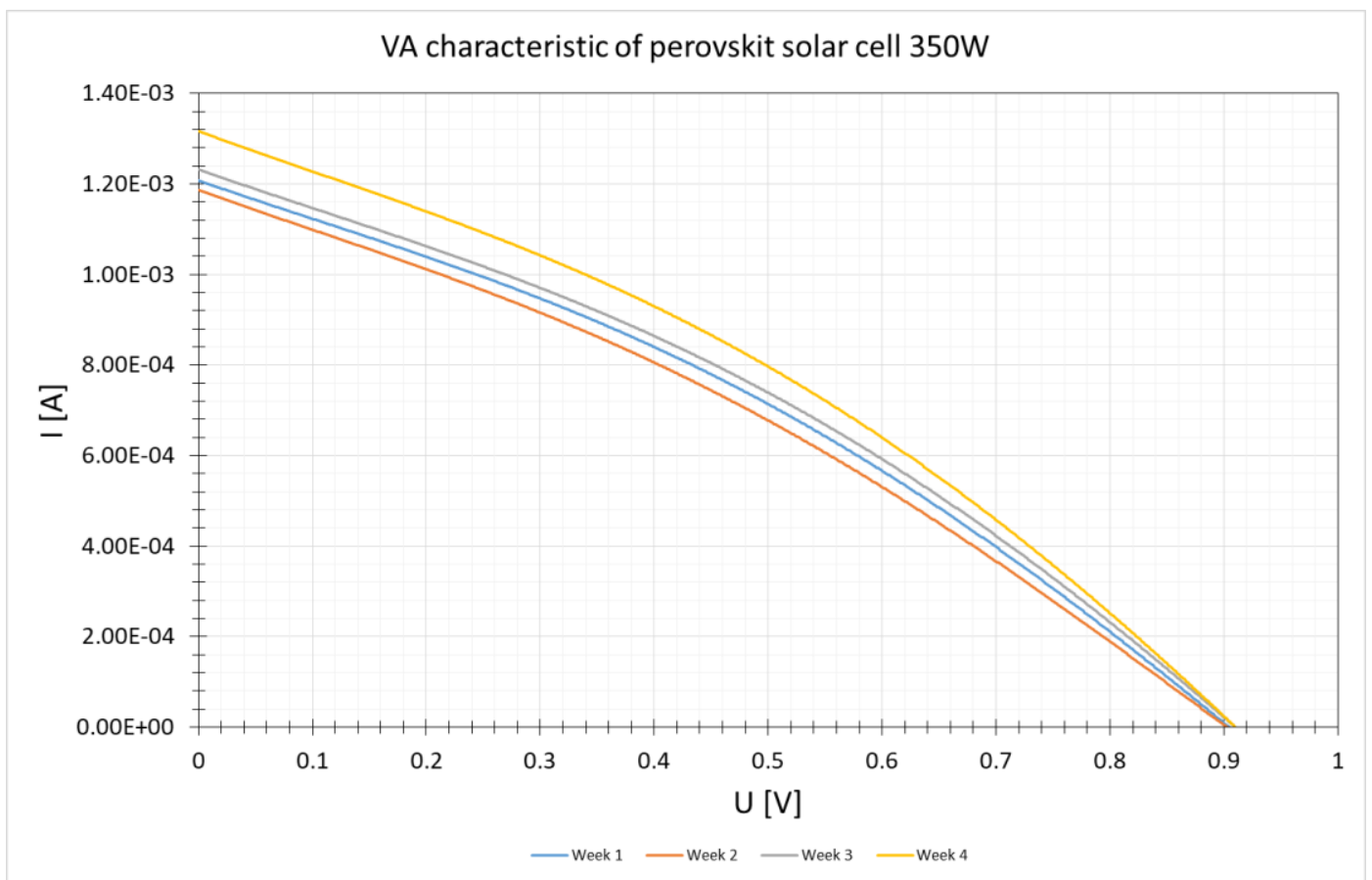

Figure 1: I-V plots during 4 weeks

I-V mesuremetnt provides us various values about perovskite solar cells. Main values, $U_{o c}$ open circuit potential, $I_{s c}$ short circuit current, $P_{\max }$ maximum power counted from $U_{\max }$ and $I_{\max }$ which represents potential and current in MPP, and Fill Factor (equation 1), are aranged in table below.

$$
F F=\frac{U_{\max } \cdot I_{\max }}{U_{O C} \cdot I_{S C}}[\%]
$$

\begin{tabular}{|r|r|r|r|r|r|r|}
\hline$E\left[W / m^{2}\right]$ & $U_{o c}[V]$ & $I_{s c}[\mathrm{~mA}]$ & $P_{\max }[\mu \mathrm{W}]$ & $\mathbf{U}_{\max }[\mathrm{V}]$ & $I_{\max }[\mu \mathrm{A}]$ & Fill Factor \\
\hline 350 & 0.907 & -1.366 & 403.8 & 0.506 & -798 & 0.326 \\
\hline
\end{tabular}

Table 1: Values measured for light intensity $350 \mathrm{~W} / \mathrm{m}^{2}$. 


\section{Dependence of photocurrent on light intensity}

This method allows to measure current during increasing light intensity of power source. This measurement was done from light intensity from 0 to $350 \mathrm{~W} / \mathrm{m}^{2}$ with step $2 \mathrm{~W} / \mathrm{m}^{2}$. Potential on solar cell was set on $0.8 \mathrm{~V}$.

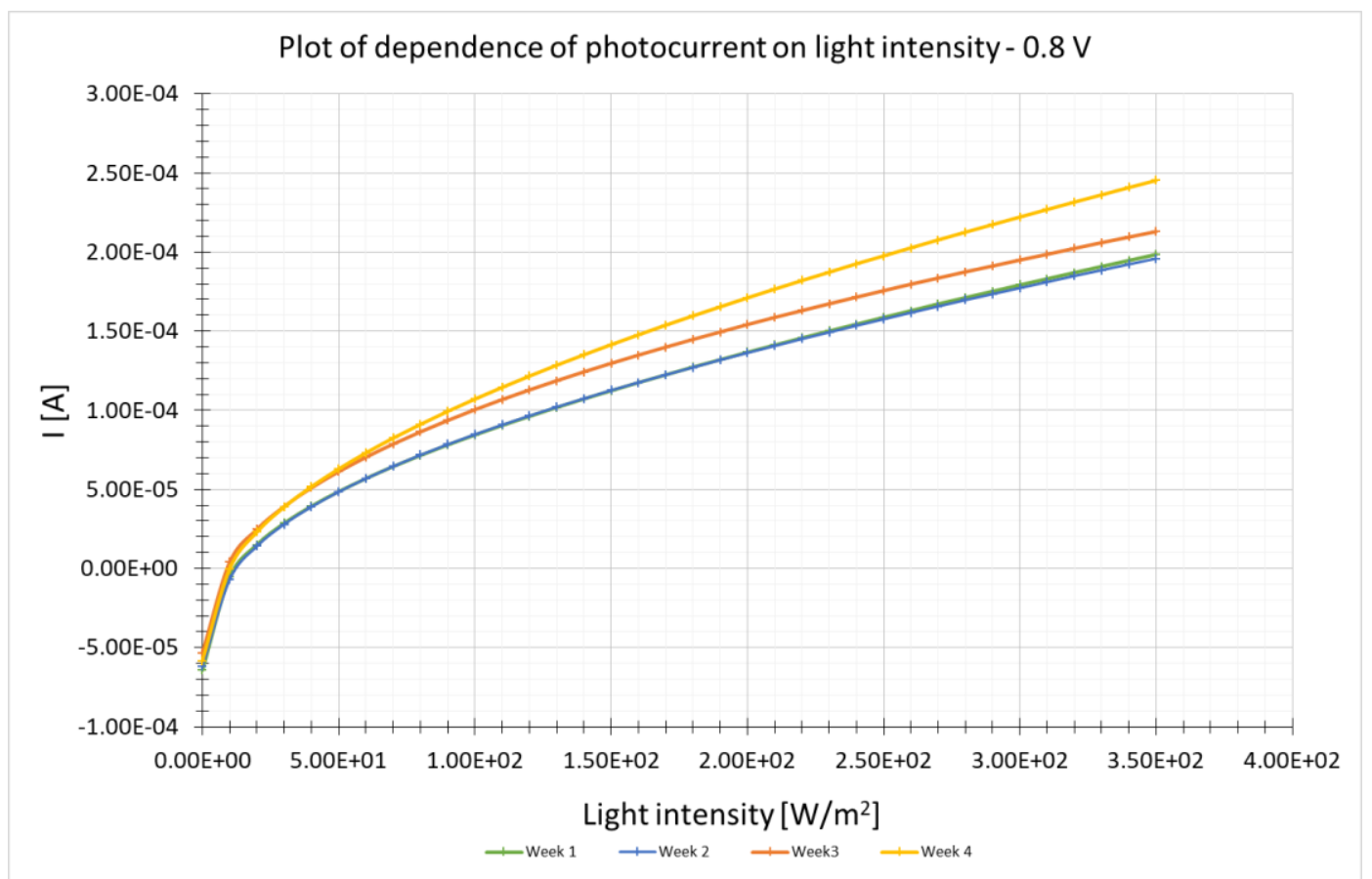

Figure 2: Plots of dependence of photocurrent on light intensity during 4 weeks

\section{Intensity modulated photocurrent spectroscopy - IMPS}

Dynamic measurements IMPS measure currents dependence and phase on frequency. Light intensity was set on $350 \mathrm{~W} / \mathrm{m}^{2}$ and frequency range from $0.1 \mathrm{~Hz}$ to $7 \mathrm{MHz}$

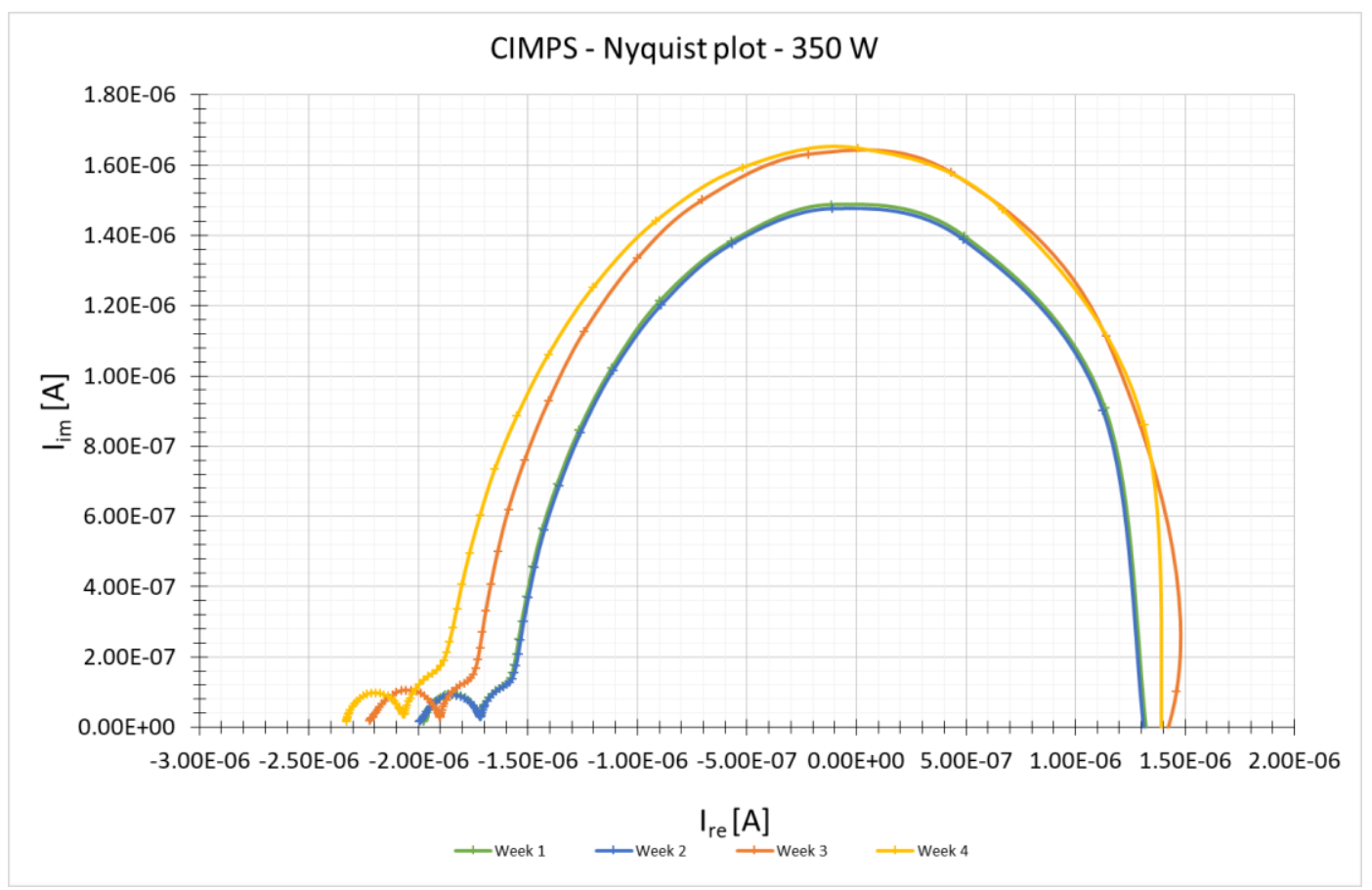

Figure 3: IMPS Nyquist plots during 4 weeks 


\section{RESULTS AND CONCLUSION}

From experiments we can see that time affects performance of perovskite solar cells. In comparison of week 1 and 2 there is slight decrease in potential and current, but in upcoming weeks 3 and 4 an increase of these values was measured. There are many variables, which can affect degradation of perovskite solar cells. This result suggests studying changes in perovskite solar cells more accurate.

For next study can be used for example IMPS or IMVS (intensity modulated photovoltage spectroscopy) method.

Data from IMPS provides us values which can be used for calculation of electron transport time $\tau_{\text {tr }}$ in perovskite solar cells (equitation 2). At short-circuit conditions, the band gap between valence and conductive band is maximum. This leads to stage, when nearly no electrons are injected into conductional band. Most reactions occur on the back layer of the anode and electrons are migrating from the location of their generation to the electrode's back layer [2].

$$
\tau_{t r}=\frac{1}{2 \cdot \pi \cdot f_{I M P S}}
$$

Where $f_{\text {IMPS }}$ is frequency in the peak of IMPS plot.

IMVS provides us data for calculation of electron recombination time $\tau_{\text {rec }}$ in perovskite solar cells (equitation 3). The open- circuit potential in perovskite solar cells is the maximum potential before the power is dissipated instead of being generated. During this potential, the band gap between valence band and conduction band is small. This causes that reactions on the back layer of the anode are less likely. Most generated electrons are injected into the conduction band. Because of this injection, solar cell reaches steady state in which the rate of electron injection into the conduction band is equal to the electron recombination rate [2].

$$
\tau_{r e c}=\frac{1}{2 \cdot \pi \cdot f_{I M V S}}
$$

Where $f_{\text {IMVS }}$ is frequency in the peak of IMVS plot.

Results from these measurements can help us understand perovskite solar cells mechanisms.

\section{REFERENCES}

[1] DVOŘÁK, T. Characterization of the perovskite photovoltaic cells. Brno: Brno University of technology, Faculty of electrical engineering and communication, 2017. 74 s. Supervisor doc. Ing. Vítězslav Novák, Ph.D.

[2] Dye Solar Cells - Part 3: IMPS and IMVS Measurements. Gamry.com: Dye Solar Cells [online] [cit. 2018-01-28]. Available from: https://www.gamry.com/applicationnotes/physechem/dye-solar-cells-imps-imvs/ 